Links have been made at both local and strategic levels within both learning disability and specialist palliative care services. All 9 learning disability teams and 6 hospices within NHS GG\&C have access to this project.

Strategically the project sits within the current learning disability strategy and although all 6 hospices are independent in their delivery of care, Chief Executives have demonstrated their commitment to the project.

All education events are evaluated and the evaluations have been extremely positive, with staff suggesting that the education provided will have a direct impact on their professional development and provision of best quality patient care for PWLD.

PWLD are at the heart of this project with the ultimate aim being to improve their care.

\section{P169 REACHING MORE PEOPLE AT THE END OF LIFE THROUGH DIGITAL COMMUNICATION}

${ }^{1}$ Kimberley McLaughlin, ${ }^{2}$ Daniel Miller. ${ }^{1}$ The Hospice of St Francis, Berkhamsted, UK, ${ }^{2}$ University of London

\subsection{6/bmjspcare-2013-000591.191}

End of Life care is arguably both a public health and diagnosis specific concern. Those living and dying from life threatening illness access support and care from formal (e.g. health and social care) and informal (e.g. community, friends and family) networks. The last few years has seen an explosion in social media and new communication technologies in the informal arena. As hospices face the challenge of extending their reach and realigning their existing resources, researching new ways to support patients and their families is key.

A 3 year collaborative study between Professor Daniel Miller (Department of Anthropology, University College London) and Kimberley McLaughlin, Director of Supportive Care (Hospice of St Francis) focuses on the hospice, patients and those living in the community.

Aims

- To understand the impact and future potential of new communication technologies e.g.webcam, social networking sites and smart phones.

- To gain the widest and deepest understanding of the role of these technologies in all aspects of communication between people in end of life situations, their carers, family and friends.

- To research issues including privacy, feelings of security and vulnerability, loneliness, boredom, memorialisation and sense of connexion with others.

- To explore the relationship between any sense of loss of communicative capacity for persons and simultaneously a gain in communicative capacity as a result of new technologies.

- To understand the use of communication technologies and health care professionals/hospice staff.

This research will

- Advance the body of knowledge regarding the use of social media in end of life care as well as researching in sensitive areas.

- Provide guidance in the use of social media in end of life care.

- Facilitate communication between end of life individuals who remain in their home and with carers, friends and families both during this period and following upon their death.

\section{P170 DIGITAL LIFE, DIGITAL DEATH - AN APP TO FILL THE GAP}

Ros Taylor, Victoria Moore, Kimberley McLaughlin, Sarah Russell. Hospice of St Francis, Berkhamsted, UK

\subsection{6/bmjspcare-2013-000591.192}

Context The crisis of illness provokes people to review their life, dwell on regrets and unfinished business, think about bucket lists and maybe their funeral.

This critical time however is dominated by treatment, panic and anxiety, and these important tasks are often neglected and delayed.

Lawyer, Victoria Moore and business partner Morag Cormack have designed a simple, elegant iPhone App to digitally capture life's special moments, in the midst of life, long before an illness takes hold.

Victoria was inspired to create the Legacy Organiser App after completing her will - she felt there was so much more to record than simply 'who gets what'!

The Legacy Organiser App allows you to:

- Save photos for your 'life album'

- Choose music to create the 'soundtrack of your life'

- Create a 'bucket list'

- Record your life lessons, your biggest regret, your best kiss!

- The 'farewell and will' section lets you record funeral wishes

Palliative Potential This innovative app provides opportunities for those in the palliative phase to:

- Use as a therapeutic digital tool to provoke new conversations

- 'Tell me about that regret', 'talk me through your bucket list'

- 'Have you thought about how you might celebrate your life?'

- Use as an advance care planning platform to capture wishes, not simply about funerals but about preferences for future care.

- Create a generativity document (Chochinov Dignity Therapy)

- Carry choices around with them - mobile phones allow instant access and sharing of key preferences with others

Next steps

1. Therapeutic pilot with 10 patients

- download App to patients iPhone

- demonstrate potential

- homework to complete a section eg bucket list

$\circ$ review together at next clinic.

First impressions - patients love it, provoking different conversations!

2. Evaluation questionnaire currently in design.

3. Co-create new sections to support advance care planning eg care preferences, with App inventor Victoria Moore 